\title{
One-pot four-component reaction for convenient synthesis of functionalized 1-benzamidospiro[indoline-3,4'-pyridines]
}

\author{
Chao Wang, Yan-Hong Jiang and Chao-Guo Yan*
}

\author{
Full Research Paper \\ Address: \\ College of Chemistry \& Chemical Engineering Yangzhou University, \\ Yangzhou 225002, China \\ Email: \\ Chao-Guo Yan* - cgyan@yzu.edu.cn \\ * Corresponding author \\ Keywords: \\ acetylenedicarboxylate; benzohydrazide; 1,4-dihydropyridine; \\ multicomponent reaction; one-pot reaction; \\ spiro[indoline-3,4'-pyridine]
}

Beilstein J. Org. Chem. 2014, 10, 2671-2676.

doi:10.3762/bjoc. 10.281

Received: 28 June 2014

Accepted: 30 October 2014

Published: 14 November 2014

This article is part of the Thematic Series "Multicomponent reactions II".

Guest Editor: T. J. J. Müller

(C) 2014 Wang et al; licensee Beilstein-Institut.

License and terms: see end of document.

\begin{abstract}
The one-pot four-component reaction of benzohydrazide (2-picolinohydrazide), acetylenedicarboxylate, isatins and malononitrile (ethyl cyanoacetate) with triethylamine as base catalyst afforded functionalized 1-benzamidospiro[indoline-3,4'-pyridines] in good yields. ${ }^{1} \mathrm{H}$ NMR spectra indicated that an equilibrium of cis/trans-conformations exist in the obtained products.
\end{abstract}

\section{Introduction}

The spirooxindole system is the core structure of many natural products and pharmaceutically important structures with notable structural complexity and biological activities of great interest [1-4]. Accordingly, many efficient and practical synthetic procedures have emerged for the synthesis of versatile spirooxindole-fused heterocycles [5-9]. In recent years, because of the emphasis on the development of green and sustainable chemistry, multicomponent reactions have been developed as efficient and potent tools for the preparation of structurally diverse molecules. Practically, multicomponent reactions based on the versatile reactivity of isatins and their 3-methylene derivatives have emerged in large numbers and become the new efficient protocols for the synthesis of various spirooxindoles [10-13].

On the other hand, the chemistry of Huisgen's 1,4-dipoles, which are simply produced from the addition of nitrogen- containing nucleophiles to electron-deficient alkynes has aroused a lot of interest in organic synthesis due to its convenient formation and versatile reactivity [14,15]. The in situ formed Huisgen's 1,4-dipoles were subsequently entrapped by various electrophiles and other reagents to finish a number of carbon-carbon bond formation reactions and heterocyclic construction processes [16-18]. A literature survey indicated that the common nitrogen-containing nucleophiles for generation of Huisgen's 1,4-dipoles are aromatic heterocycles such as $\mathrm{N}$-alkylimidazole, pyridine, quinoline, isoquinoline and primary aromatic amines. In recent years, other nitrogen-containing nucleophiles such as hydrazine and arylhydrazines are also used to generate Huisgen's 1,4-dipoles in domino reactions [19-21]. Recently, we and Perumal have demonstrated that the fourcomponent reaction of arylamine, acetylenedicarboxylate, isatin and malononitrile can afford the spiro[indoline-3,4'-pyridine] 
derivatives in satisfactory yields [22-24]. We envisioned that functionalized spiro[indoline-3,4'-pyridine] derivatives can be synthesized by employing other nitrogen-containing nucleophiles such as hydrazine and imines in the similar four-component reactions. In fact, the four-component reaction of hydrazine, acetylenedicarboxylate, isatin and malononitrile for the formation of spiro[indoline-3,4'-pyrano[2,3-c]pyrazoles] have been developed very recently by several groups [25-27]. Against this background and in continuation of our efforts toward the development of practical multicomponent reactions based on the reactivity of isatin and its derivatives [28-34], we herein wish to report the efficient synthesis of functionalized 1-benzamidospiro[indoline-3,4'-pyridines] via one-pot fourcomponent reactions of benzohydrazide, acetylenedicarboxylate, isatin and malononitrile.

\section{Results and Discussion}

According to the reaction conditions of the previously reported four-component reaction for the efficient synthesis of the functionalized spiro[indoline-3,4'-pyridine] derivatives [23] a mixture of benzohydrazide and dimethyl acetylenedicarboxylate in ethanol was firstly stirred at room temperature for about fifteen minutes. Then isatin and malononitrile as well as triethylamine as the base catalyst were introduced into reaction system. The subsequent reaction proceeded very smoothly at room temperature to give the 1'-benzamidospiro[indoline-3,4'-pyridines] 1a-d in satisfactory yields (Table 1, entries 1-4). It is known that hydrazine reacts firstly with acetylenedicarboxylate to give the pyrazolone intermediate in the previously reported multicomponent reactions containing hydrazine and acetylenedicarboxylate [25-27]. Here, due to the protection of the benzoyl group, only the free amino group in benzohydrazide took part in the reaction to give the 1'-benzamido-substituted spiro[indoline3,4'-pyridine]. It should be noted that pure products can be obtained by washing the formed precipitates from the reaction solution and no further purification process is needed. The similar reactions with ethyl cyanoacetate also produced the spiro compounds $\mathbf{1 e}-\mathbf{i}$ in $68-74 \%$ (Table 1, entries 5-9). The substituents on the isatins showed little effect on the yields. Further, 2-picolinohydrazide can also be utilized in the fourcomponent reactions to give the corresponding 1'-picolinamidospiro[indoline-3,4'-pyridines] $\mathbf{1} \mathbf{j}-\mathbf{m}$ in satisfactory yields (Table 1, entries 10-13). These results indicate that this fourcomponent reaction may have a widely variety of substrates.

Table 1: Synthesis of spiro[indoline-3,4'-pyridines] 1a-m via four-component reaction. ${ }^{\text {a }}$

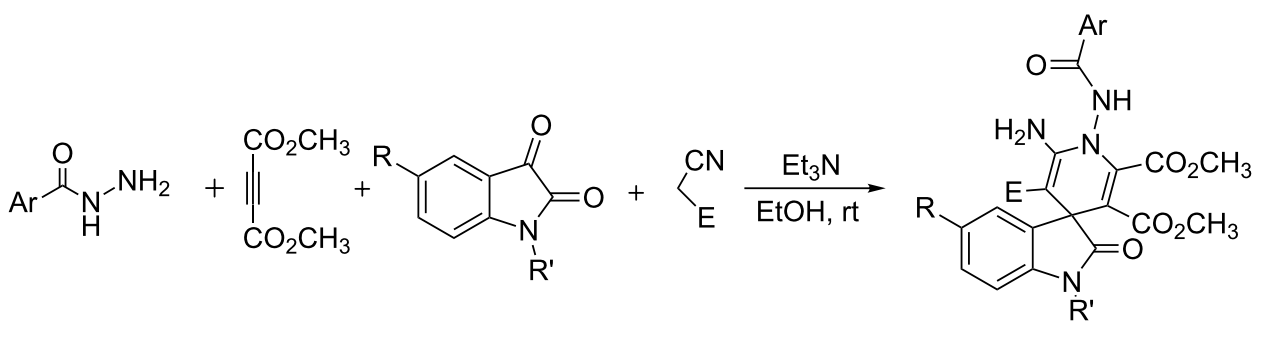

$1 a-m$

\begin{tabular}{|c|c|c|c|c|c|c|}
\hline Entry & Compd & $\mathrm{Ar}$ & $\mathrm{R}$ & $\mathrm{R}^{\prime}$ & $E$ & Yield $(\%, \text { cis/trans })^{\mathrm{b}}$ \\
\hline 1 & $1 a$ & $\mathrm{C}_{6} \mathrm{H}_{5}$ & $\mathrm{H}$ & $\mathrm{CH}_{2} \mathrm{C}_{6} \mathrm{H}_{4}$ & $\mathrm{CN}$ & $72(4: 1)$ \\
\hline 2 & $1 \mathrm{~b}$ & $\mathrm{C}_{6} \mathrm{H}_{5}$ & $\mathrm{~F}$ & $\mathrm{CH}_{2} \mathrm{C}_{6} \mathrm{H}_{4}$ & $\mathrm{CN}$ & $84(6.5: 1)$ \\
\hline 3 & $1 c$ & $p-\mathrm{CH}_{3} \mathrm{C}_{6} \mathrm{H}_{4}$ & $\mathrm{H}$ & $\mathrm{H}$ & $\mathrm{CN}$ & 78 \\
\hline 4 & $1 d$ & $p-\mathrm{CH}_{3} \mathrm{C}_{6} \mathrm{H}_{4}$ & $\mathrm{~F}$ & $\mathrm{CH}_{2} \mathrm{C}_{6} \mathrm{H}_{4}$ & $\mathrm{CN}$ & $65(6.5: 1)$ \\
\hline 5 & $1 e$ & $\mathrm{C}_{6} \mathrm{H}_{5}$ & $\mathrm{H}$ & $\mathrm{H}$ & $\mathrm{CO}_{2} \mathrm{Et}$ & $74(5: 1)$ \\
\hline 6 & $1 f$ & $\mathrm{C}_{6} \mathrm{H}_{5}$ & $\mathrm{Cl}$ & $\mathrm{H}$ & $\mathrm{CO}_{2} \mathrm{Et}$ & $70(5: 1)$ \\
\hline 7 & $1 \mathrm{~g}$ & $\mathrm{C}_{6} \mathrm{H}_{5}$ & $\mathrm{Cl}$ & $\mathrm{CH}_{2} \mathrm{C}_{6} \mathrm{H}_{4}$ & $\mathrm{CO}_{2} \mathrm{Et}$ & $68(6: 1)$ \\
\hline 8 & $1 \mathrm{~h}$ & $p-\mathrm{CH}_{3} \mathrm{C}_{6} \mathrm{H}_{4}$ & $\mathrm{Cl}$ & $\mathrm{H}$ & $\mathrm{CO}_{2} \mathrm{Et}$ & $69(5: 1)$ \\
\hline 9 & $1 \mathrm{i}$ & $p-\mathrm{CH}_{3} \mathrm{C}_{6} \mathrm{H}_{4}$ & $\mathrm{Cl}$ & $\mathrm{CH}_{2} \mathrm{C}_{6} \mathrm{H}_{4}$ & $\mathrm{CO}_{2} \mathrm{Et}$ & $70(6.5: 1)$ \\
\hline 10 & $1 \mathbf{j}$ & $2-\mathrm{C}_{5} \mathrm{H}_{4} \mathrm{~N}$ & $\mathrm{CH}_{3}$ & $\mathrm{H}$ & $\mathrm{CO}_{2} \mathrm{Et}$ & $80(5: 1)$ \\
\hline 11 & $1 \mathrm{k}$ & $2-\mathrm{C}_{5} \mathrm{H}_{4} \mathrm{~N}$ & $\mathrm{Cl}$ & $\mathrm{H}$ & $\mathrm{CO}_{2} \mathrm{Et}$ & $82(4: 1)$ \\
\hline 12 & 11 & $2-\mathrm{C}_{5} \mathrm{H}_{4} \mathrm{~N}$ & $\mathrm{Cl}$ & $\mathrm{CH}_{2} \mathrm{C}_{6} \mathrm{H}_{4}$ & $\mathrm{CO}_{2} \mathrm{Et}$ & $68(5: 1)$ \\
\hline 13 & $1 \mathrm{~m}$ & $2-\mathrm{C}_{5} \mathrm{H}_{4} \mathrm{~N}$ & $\mathrm{CH}_{3}$ & $\mathrm{CH}_{2} \mathrm{C}_{6} \mathrm{H}_{4}$ & $\mathrm{CO}_{2} \mathrm{Et}$ & $81(3: 1)$ \\
\hline
\end{tabular}

aReaction conditions: arylhydrazide $(1.0 \mathrm{mmol})$, acetylenedicarboxylate $(1.0 \mathrm{mmol})$ in $\mathrm{EtOH}(15.0 \mathrm{~mL}), \mathrm{rt}, 15 \mathrm{~min}$; isatin $(1.0 \mathrm{mmol})$, malononitrile or ethyl cyanoacetate $(1.0 \mathrm{mmol}), \mathrm{Et}_{3} \mathrm{~N}(0.2 \mathrm{mmol})$, rt, $24 \mathrm{~h}$; blsolated yield. 
The structures of the prepared spiro[indoline-3,4'-pyridines] 1a-m were fully characterized with IR, ${ }^{1} \mathrm{H},{ }^{13} \mathrm{C}$ NMR, HRMS spectra and were further confirmed by single-crystal X-ray diffraction determination of the compound $\mathbf{1 k}$ (Figure 1). The ${ }^{1} \mathrm{H}$ NMR spectra of compounds $\mathbf{1 a}-\mathbf{m}$ usually showed that two diastereoisomers with a ratio in range of $3: 1$ to $6.5: 1$ exist in the obtained products. But there is only one diastereoisomer in the product 1c according to its ${ }^{1} \mathrm{H}$ NMR spectrum. For an example, in the ${ }^{1} \mathrm{H}$ NMR spectrum of compound 1a, the amido group displays two singlets with a ratio of $4: 1$ at 11.46 and $11.38 \mathrm{ppm}$. The two singlets at 3.65 and $3.25 \mathrm{ppm}$ are the signals of the two methoxy groups in the major isomer and the two singlets at 3.60 and $3.17 \mathrm{ppm}$ are characteristic for the two methoxy groups in the minor isomer. From the molecular structure of spiro compound $1 \mathbf{k}$ (Figure 1), it can be seen that the four carbon atoms and the nitrogen atom in the newly formed 1,4-dihydropyridyl ring exist nearly in one plane, while the C-4' atom slightly deviates in this plane $(0.318(4) \AA)$. The phenyl group of the oxindole moiety and the 1'-picolinamido group exist in the same side of the 1,4-dihydropyridyl plane. By observing the crystal structure of spiro compound $\mathbf{1 k}$, we could conclude that the 1 '-picolinamido group might exist in cis-or trans-position of the phenyl group of the oxindole moiety. Thus, the cis/transconformations are in a dynamic equilibrium by inversion of the 1'-benzamido group (Scheme 1). The cis-conformation cannot be easily converted to the trans-conformation because the neighboring amino and methoxycarbonyl groups exhibit some steric hindrance for the inversion of the 1'-benzamido group. The ${ }^{1} \mathrm{H}$ NMR spectra clearly indicated the existence of cis/ trans-conformations.

In order to explain the formation of the spiro[indoline-3,4'pyridines], a rational reaction mechanism is briefly proposed on the basis of similar reactions of Huigen's 1,4-dipoles [22-24] (Scheme 2). Firstly, the addition of benzohydrazide to acetylenedicarboxylate results in an active zwitterionic intermediate (A). In the meantime, the condensation of isatin with

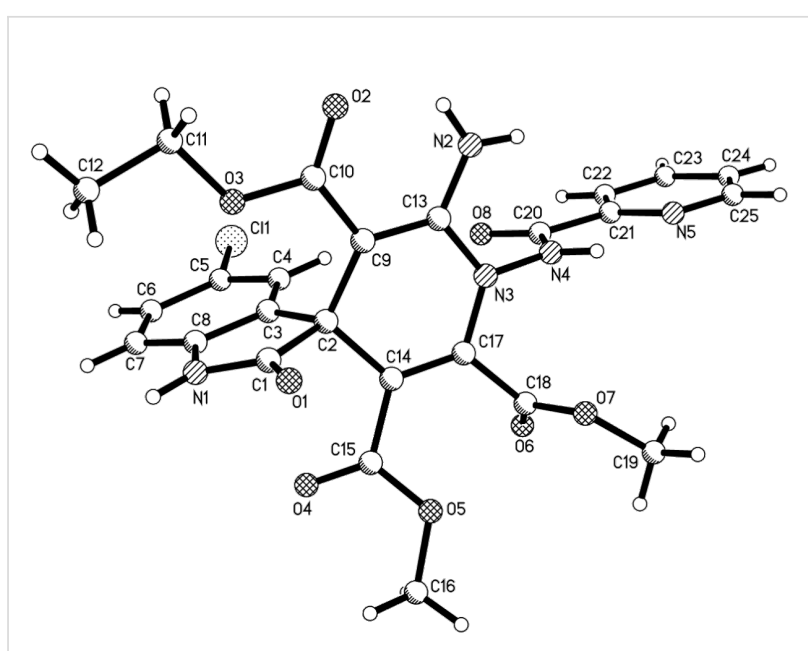

Figure 1: Molecular structure of spiro[indoline-3,4'-pyridine] 1k.

malononitrile or ethyl cyanoacetate in the presence of triethylamine affords isatylidenemalononitrile or its derivative (B). Then the nucleophilic addition of the zwitterionic intermediate (A) to isatylidenemalononitrile (B) produces the adduct $(\mathbf{C})$, which in turn transferres to intermediate (D) by immigration of a proton from the nitrogen atom to the carbon atom. Thirdly, the intramolecular reaction of the amino group with the cyano group gives a cyclized intermediate $(\mathbf{E})$. Finally, the imino-enamino tautomerization results in the final spiro compound $\mathbf{1}$. In this process, the initially formed zwitterrionic intermediate (A) does not cyclize to give pyrazolone intermediate as in the reaction of hydrazine with acetylenedicarboxylate. Thus, benzohydrazide shows very different reactivity to that of hydrazine in the four-component reaction.

\section{Conclusion}

In summary, we have investigated the four-component reactions of benzohydrazide, acetylenedicarboxylate, isatins and malononitrile or ethyl cyanoacetate and successfully developed

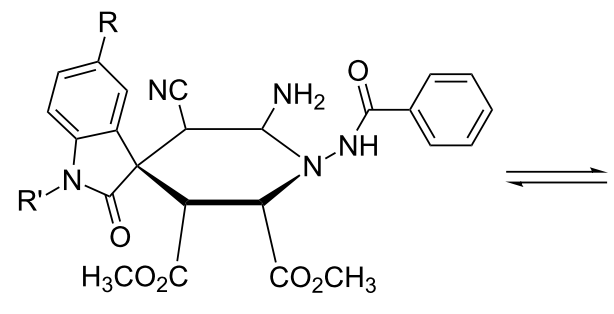

cis-conformation

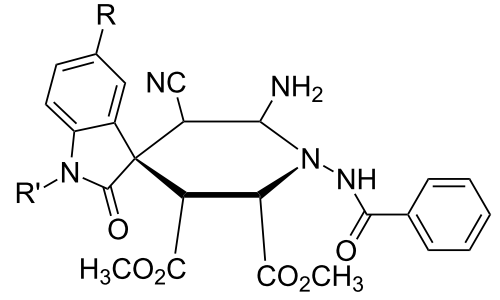

trans-conformation 


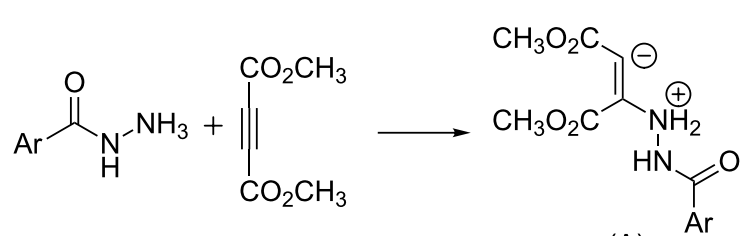

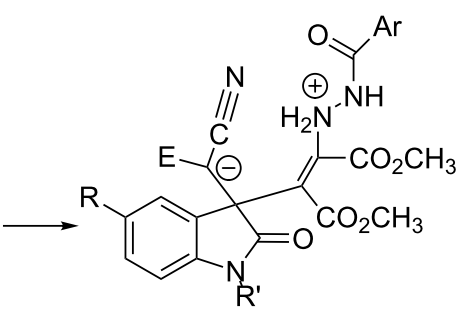

$(B)^{R^{\prime}}$

(C)

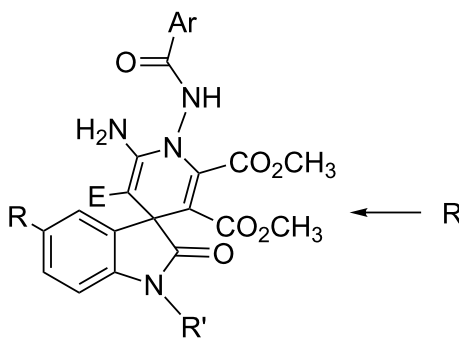

1

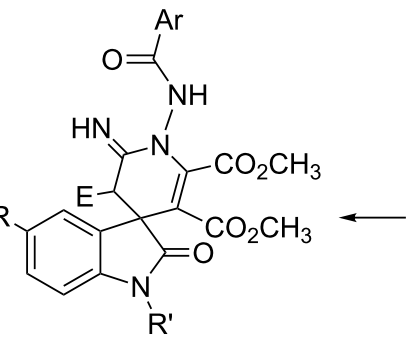

(E)

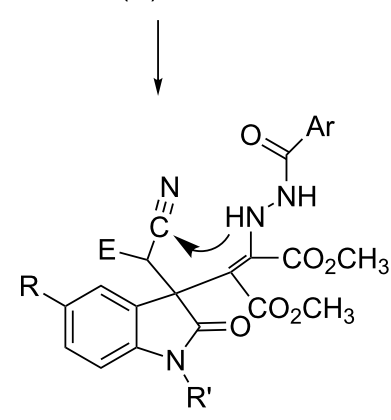

(D)

Scheme 2: Proposed reaction mechanism for the four-component reaction.

an efficient synthetic procedure for the preparation of functionalized 1-benzamidospiro[indoline-3,4'-pyridines]. Furthermore, the reaction mechanism and the dynamic equilibrium of cis/trans-conformations were also briefly discussed. This reaction provided new examples for the development of potential applications of Huisgen's 1,4-dipoles in synthetic chemistry.

\section{Experimental}

Reagents and apparatus: All reactions were monitored by TLC. Melting points were taken on a hot-plate microscope apparatus. IR spectra were obtained on a Bruker Tensor 27 spectrometer $\left(\mathrm{KBr}\right.$ disc). ${ }^{1} \mathrm{H}$ and ${ }^{13} \mathrm{C}$ NMR spectra were recorded with a Bruker AV-600 spectrometer with DMSO- $d_{6}$ as solvent and TMS as internal standard $\left(600\right.$ and $150 \mathrm{MHz}$ for ${ }^{1} \mathrm{H}$ and ${ }^{13} \mathrm{C}$ NMR spectra, respectively). HPLC/MS were measured at Bruker MicroTOF spectrometer. Single-crystal structure was determined on Bruker Smart-2 CCD diffractometer.

\section{General procedure for the synthesis of 1,4-dihydropy-} ridines 1a-m via four-component reactions: In a round bottom flask, a solution of benzohydrazide or 2-picolinohydrazide $(1.0 \mathrm{mmol})$ and dimethyl acetylenedicarboxylate $(1.0 \mathrm{mmol})$ in ethanol $(15.0 \mathrm{~mL})$ was stirred at room temperature for about fifteen minutes. Then, isatin $(1.0 \mathrm{mmol})$, malononitrile or ethyl cyanoacetate $(1.0 \mathrm{mmol})$ and triethylamine $(0.2 \mathrm{mmol})$ was added. The mixture was stirred at room temperature for 24 hours. The resulting precipitates were collected by filtration and washed with cold alcohol to give the pure product for analysis.

Dimethyl 2'-amino-1'-benzamido-1-benzyl-3'-cyano-2-oxo$\mathbf{1}^{\prime} \boldsymbol{H}$-spiro[indoline-3,4'-pyridine]-5',6'-dicarboxylate (1a): white solid, 72\%; mp 222-224 ${ }^{\circ} \mathrm{C}$; ${ }^{1} \mathrm{H}$ NMR $(600 \mathrm{MHz}$, DMSO- $\left.d_{6}\right) \delta$ cis-isomer: $11.46(\mathrm{~s}, 1 \mathrm{H}, \mathrm{NH}), 7.90-7.89(\mathrm{~m}, 2 \mathrm{H}$, ArH), 7.65-7.62 (m, 2H, ArH), 7.55 (brs, 2H, ArH), 7.50 (brs, 2H, ArH), 7.34 (brs, 2H, ArH), 7.29-7.28 (m, 1H, ArH), 7.21 (brs, 1H, ArH), 7.10 (d, $J=7.2 \mathrm{~Hz}, 1 \mathrm{H}, \mathrm{ArH}), 6.82$ (d, $J=7.2$ $\mathrm{Hz}, 1 \mathrm{H}, \mathrm{ArH}$ ), 6.72 (brs, 2H, NH$)_{2}, 4.98$ (d, $J=15.0 \mathrm{~Hz}, 1 \mathrm{H}$, $\left.\mathrm{CH}_{2}\right), 4.82\left(\mathrm{~d}, J=15.0 \mathrm{~Hz}, 1 \mathrm{H}, \mathrm{CH}_{2}\right), 3.65\left(\mathrm{~s}, 3 \mathrm{H}, \mathrm{OCH}_{3}\right), 3.25$ (s, 3H, $\left.\mathrm{OCH}_{3}\right)$; trans-isomer: $11.38(\mathrm{~s}, 1 \mathrm{H}, \mathrm{NH}), 7.85-7.84(\mathrm{~m}$, $2 \mathrm{H}, \mathrm{ArH}), 6.79$ (brs, $\left.2 \mathrm{H}, \mathrm{NH}_{2}\right), 3.60\left(\mathrm{~s}, 3 \mathrm{H}, \mathrm{OCH}_{3}\right), 3.17$ (s, $3 \mathrm{H}$, $\left.\mathrm{OCH}_{3}\right)$; cis/trans-isomers: $4: 1 ;{ }^{13} \mathrm{C}$ NMR $(150 \mathrm{MHz}$, DMSO$\left.d_{6}\right) \delta 177.3,166.8,163.6,161.9,152.1,145.2,141.3,136.2$, $135.2,132.6,131.1,129.5,128.6,128.5,128.4,127.9,127.6$, 127.3, 124.1, 123.5, 122.8, 118.5, 108.8, 58.4, 52.9, 51.9, 49.4, 43.5; IR (KBr) v: 3456, 2952, 2186, 1708, 1654, 1613, 1575 , 1482, 1432, 1302, 1224, 1183, 1133, 1091, 1029, 936, 754, 697 $\mathrm{cm}^{-1}$; HRMS (ESI) $(\mathrm{m} / \mathrm{z}):[\mathrm{M}+\mathrm{Na}]^{+}$calcd. for $\mathrm{C}_{31} \mathrm{H}_{25} \mathrm{~N}_{5} \mathrm{NaO}_{6}$ : 586.1697; found: 586.1703 . 


\section{Supporting Information}

Experimental details and detailed spectroscopic data of all new compounds are available as Supporting Information. Single crystal data for compounds $1 \mathbf{k}$ (CCDC 1000773) has been deposited in the Cambridge Crystallographic Data Center.

\section{Supporting Information File 1}

Experimental details and spectroscopic data of all new compounds.

[http://www.beilstein-journals.org/bjoc/content/ supplementary/1860-5397-10-281-S1.pdf]

\section{Acknowledgements}

This work was financially supported by the National Natural Science Foundation of China (Grant No. 21172189) and the Priority Academic Program Development of Jiangsu Higher Education Institutions. We thank Analysis and Test Center of Yangzhou University providing all analytical instruments.

\section{References}

1. Abdel-Rahman, A. H.; Keshk, E. M.; Hanna, M. A.; El-Bady, S. M. Bioorg. Med. Chem. 2004, 12, 2483-2488.

doi:10.1016/j.bmc.2003.10.063

2. Koch, M. A.; Schuffenhauer, A.; Scheck, M.; Wetzel, S.; Casaulta, M.; Odermatt, A.; Ertl, P.; Waldmann, H. Proc. Natl. Acad. Sci. U. S. A. 2005, 102, 17272-17277. doi:10.1073/pnas.0503647102

3. Sebahar, P. R.; Williams, R. M. J. Am. Chem. Soc. 2000, 122, 5666-5667. doi:10.1021/ja001133n

4. Marti, C.; Carreira, E. M. Eur. J. Org. Chem. 2003, 2209-2219. doi:10.1002/ejoc.200300050

5. Kotha, S.; Deb, A. C.; Lahiri, K.; Manivannan, E. Synthesis 2009, 165-193. doi:10.1055/s-0028-1083300

6. Trost, B. M.; Brennan, M. K. Synthesis 2009, 3003-3025. doi:10.1055/s-0029-1216975

7. Ball-Jones, N. R.; Badillo, J. J.; Franz, A. K. Org. Biomol. Chem. 2012, 10, 5165-5181. doi:10.1039/c2ob25184a

8. Hong, L.; Wang, R. Adv. Synth. Catal. 2013, 355, 1023-1052. doi:10.1002/adsc. 201200808

9. Singh, G. S.; Desta, Z. Y. Chem. Rev. 2012, 112, 6104-6155. doi:10.1021/cr300135y

10. Mao, H.; Lin, A.; Tang, Y.; Shi, Y.; Hu, H.; Cheng, Y.; Zhu, C. Org. Lett. 2013, 15, 4062-4065. doi:10.1021/ol401595g

11. Liu, Y.; Wang, H.; Wan, J. Asian J. Org. Chem. 2013, 2, 374-386. doi:10.1002/ajoc.201200180

12. Cao, Z.-Y.; Wang, Y.-H.; Zeng, X.-P.; Zhou, J. Tetrahedron Lett. 2014, 55, 2571-2584. doi:10.1016/j.tetlet.2014.01.084

13. Cheng, D.; Ishihara, Y.; Tan, B.; Barbas, C. F., III. ACS Catal. 2014, 4, 743-762. doi:10.1021/cs401172r

14. Huisgen, R.; Morikawa, M.; Herbig, K.; Brunn, E. Chem. Ber. 1967, 100, 1094-1106. doi:10.1002/cber.19671000406

15. Huisgen, R. Z. Chem. 1968, 8, 290-298. doi:10.1002/zfch. 19680080803
16. Nair, V.; Rajesh, C.; Vinod, A. U.; Bindu, S.; Sreekanth, A. R.; Mathen, J. S.; Balagopal, L. Acc. Chem. Res. 2003, 36, 899-907. doi:10.1021/ar020258p

17. Nair, V.; Menon, R. S.; Sreekanth, A. R.; Abhilash, N.; Biju, A. T. Acc. Chem. Res. 2006, 39, 520-530. doi:10.1021/ar0502026

18. Nair, V.; Deepthi, A.; Ashok, D.; Raveendran, A. E.; Paul, R. R. Tetrahedron 2014, 70, 3085-3105. doi:10.1016/j.tet.2014.03.014

19. Kielland, N.; Lavilla, R. Top. Heterocycl. Chem. 2010, 25, 127-168. doi:10.1007/7081_2010_42

20. Shaabani, A.; Maleki, A.; Rezayan, A. H.; Sarvary, A. Mol. Diversity 2011, 15, 41-68. doi:10.1007/s11030-010-9258-1

21. Han, Y.; Sun, J.; Sun, Y.; Gao, H.; Yan, C. Chin. J. Org. Chem. 2012, 32, 1577-1586. doi:10.6023/cjoc201206008

22. Kiruthika, S. E.; Lakshmi, N. V.; Banu, B. R.; Perumal, P. T. Tetrahedron Lett. 2011, 52, 6508-6511. doi:10.1016/j.tetlet.2011.09.119

23. Sun, J.; Wu, Q.; Zhang, L.; Yan, C. Chin. J. Chem. 2012, 30, 1548-1554. doi:10.1002/cjoc.201100657

24. Zhang, L.-J.; Wu, Q.; Sun, J.; Yan, C.-G. Beilstein J. Org. Chem. 2013, 9, 846-851. doi:10.3762/bjoc.9.97

25. Pal, S.; Khan, M. N.; Karamthulla, S.; Abbas, S. J.; Choudhury, L. H. Tetrahedron Lett. 2013, 54, 5434-5440. doi:10.1016/j.tetlet.2013.07.117

26. Pore, D. M.; Patil, P. B.; Gaikwad, D. S.; Hegade, P. G.; Patil, J. D.; Undale, K. A. Tetrahedron Lett. 2013, 54, 5876-5878. doi:10.1016/j.tetlet.2013.08.084

27. Feng, J.; Ablajan, K.; Sali, A. Tetrahedron 2014, 70, 484-489. doi:10.1016/j.tet.2013.11.019

28. Sun, Y.; Sun, J.; Yan, C.-G. Tetrahedron Lett. 2012, 53, 3647-3649. doi:10.1016/j.tetlet.2012.05.023

29. Han, Y.; Wu, Q.; Sun, J.; Yan, C.-G. Tetrahedron 2012, 68, 8539-8544. doi:10.1016/j.tet.2012.08.030

30. Sun, J.; Sun, Y.; Gao, H.; Yan, C.-G. Eur. J. Org. Chem. 2012, 1976-1983. doi:10.1002/ejoc.201101737

31. Wu, L.; Sun, J.; Yan, C.-G. Org. Biomol. Chem. 2012, 10, 9452-9463. doi:10.1039/c2ob26849c

32. Sun, Y.; Sun, J.; Yan, C.-G. Beilstein J. Org. Chem. 2013, 9, 8-14. doi:10.3762/bjoc.9.2

33. Fu, Q.; Yan, C.-G. Beilstein J. Org. Chem. 2013, 9, 918-924. doi:10.3762/bjoc.9.105

34. Gao, H.; Sun, J.; Yan, C.-G. J. Org. Chem. 2014, 79, 4131-4136. doi:10.1021/jo500144z 


\section{License and Terms}

This is an Open Access article under the terms of the Creative Commons Attribution License

(http://creativecommons.org/licenses/by/2.0), which permits unrestricted use, distribution, and reproduction in any medium, provided the original work is properly cited.

The license is subject to the Beilstein Journal of Organic Chemistry terms and conditions:

(http://www.beilstein-journals.org/bjoc)

The definitive version of this article is the electronic one which can be found at:

doi:10.3762/bjoc.10.281 